$$
\begin{aligned}
& \text { CONF-950201--25 } \\
& \text { F9SO5-92ER } 75784
\end{aligned}
$$

Effect of Neutron Irradiation on Mechanical Properties of Ferritic Steels

\author{
by \\ Stephen B. Kass and K. Linga Murty \\ in Proceedings of TMS-symposium (Las Vegas, NV, Feb. 1995) on \\ Microstructures and Mechanical Properties of AGing Materials II \\ P. K. Liaw, et al (Eds.) \\ TMS (1996) pp. $27-35$
}

DISTRISUTION OF TMIS DOCUMENT is UNEMATED ph MASTER 


\section{DISCLAIMER}

This report was prepared as an account of work sponsored by an agency of the United States Government. Neither the United States Government nor any agency thereof, nor any of their employees, makes any wartanty, express or implied, or assumes any legal liability or responsibility for the accuracy, completeness, or usefulness of any information, apparatus, product, or process disclosed, or represents that its use would not infringe privately owned rights. Reference berein to any specific commercial product, process, or service by trade name, trademark, inanufacturer, or otherwise does not necessarily constitute or imply its endorsement, recom. mendation, or favoring by the United States Government or any ageacy thereof. The views and opinions of authors expressed herein do not necessarily state or reflect those of the United States Governmeat or any agency thereof. 


\section{DISCLAIMER}

Portions of this document may be illegible in electronic image products. Images are produced from the best available original document. 


\title{
Effect of Neutron Irradiation on Mechanical Properties of Ferritic Steels
}

\author{
Stephen B. Kass and K. Linga Murty \\ North Carolina State University \\ Raleigh, North Carolina 27695-7909
}

\begin{abstract}
$\underline{\text { Abstract }}$
Effect of neutron radiation exposure was investigated in various ferritic steels with the main emphasis being the effects of thermal neutrons on radiation hardening. Pure iron of varied grain sizes was also used for characterizing the grain size effects on the source hardening before and after neutron irradiation. While many steels are considered in the overall study, the results on 1020, A516 and A588 steels are emphasized. Radiation hardening due to fast neutrons was seen to be sensitive to the composition of the steels with A354 being the least resistant and A.490 the least sensitive. Majority of the radiation hardening stems from friction hardening, and source hardening term decreased with exposure to neutron radiation apparently due to the interaction of the interstitial impurities with radiation produced defects. Inclusion of thermal neutrons along with fast resulted in further decrease in the source hardening with a slight increase in the friction hardening which revealed a critical grain size below which exposure to total (fast and thermal) neutron spectrum resulted in a slight reduction in the yield stress compared to the exposure to only fast neutrons. This is the first time such a grain size effect is reported and this is shown to be consistent with known radiation effects on friction and source hardening terms along with the observation that low energy neutrons have a nonnegligible effect on the mechanical properties of steels. In ferritic steels, however, despite their small grain size, exposure to total neutron spectrum yielded higher strengths than exposure to only fast neutrons. This behavior is consistent with the fact that the source hardening is small in these alloys and radiation effect is due only to friction stress.
\end{abstract}

\section{Introduction}

Ferritic steels find many applications in fission reactors such as in the construction of pressure vessels in light water reactors, reactor support structures, steam generator housings in liquid metal fast breeder reactors, etc. Radiation embrittlement of ferritic steels, used for pressure boundary applications, in terms of decreased upper shelf energy accompanied by increased transition temperature is usually monitored from Charpy impact tests on specimens fabricated from base, weld and heat-affected zone materials through surveillance programs in operating power reactors. The extensive data base on various reactor vessel surveillance capsule programs revealed the 
influence of alloying elements such as $\mathrm{Cu}, \mathrm{Ni}$ and $\mathrm{P}$ on the changes in DBTT and upper shelf energy along with the superimposed effects of radiation fluence and irradiation temperature [1 - 3]. Degree of radiation embrittlement of these materials is a function of neutron flux, irradiation temperature and time, as well as the composition of the steels. Effects of alloying and impurity elements such as $\mathrm{P}, \mathrm{Cu}, \mathrm{Ni}$ etc have been well characterized resulting in modern vessel materials and welding techniques with reduced amounts of these trace impurities. In addition, the effects of interstitial impurities such as $\mathrm{C}$ and $\mathrm{N}$ on the mechanical and fracture behaviors of these materials through strain aging have recently been shown to result in dips in the shelf energies and ductilities when plotted as a function of the test temperature $[4,5]$. Moreover, recent findings on materials irradiated in HFIR revealed sensitivity of radiation embrittlement on neutron flux spectrum [6]. While it was thought in the past that only fast neutrons are responsible for changes in macroscopic properties of materials, these experimental investigations and recent computer simulations clearly showed that thermal and epithermal neutrons may make nonnegligible contribution to the overall damage both in terms of microscopic defect production as well as the macroscopic property changes [6]. Thus one of the major goals of the current study has been to isolate the effects of fast and thermal neutrons on changes in the mechanical properties of ferritic steels. For an understanding of the underlying mechanisms, relatively pure Armco-iron and silicon-killed mild steel are used along with a number of low alloy steels of varied compositions. While an extensive matrix of ferritic steels with different compositions has been under study, we present here the experimental results on A516Gr70 and 1020 typically used for reactor supports, A588 used for reactor pressure vessel, and Armco-iron of varying grain sizes $(50-300 \mu \mathrm{m})$.

A major objective of the present study has been to investigate the effect of low energy $(\leq 0.5 \mathrm{eV})$ neutrons at low irradiation temperatures $\left(-50^{\circ} \mathrm{C}\right)$ on the mechanical and fracture characteristics of ferritic steels. This paper presents mainly the tensile test data at ambient following radiation exposure where some of the samples were wrapped with cadmium to shield neutrons with energies less than $\sim 0.5 \mathrm{eV}$, and the results are interpreted in terms of radiation effects on friction and source hardening components comprising the yield strength $[7,9]$,

$$
\sigma_{y}=\sigma_{i}+\sigma_{s}=\sigma_{i}+\frac{k_{y}}{\sqrt{D}} \text {. }
$$

The significance of the partitioning of the yield strength into friction and source hardening terms lies in the fact that the transition temperature from ductile to brittle fracture regimes may be evaluated using Cottrell brittle fracture theory [7]:

$$
\Delta \mathrm{DBTT}=-\frac{1+\frac{2 \Phi^{2} \sigma_{\mathrm{y}}}{\sigma_{\mathrm{i}}}\left(\frac{\mathrm{d} \sigma_{\mathrm{s}}}{\mathrm{d} \Phi}\right)}{1+\frac{\sigma_{\mathrm{y}}}{\sigma_{\mathrm{s}}}\left(\frac{\mathrm{d} \sigma_{\mathrm{s}}}{\mathrm{dT}}\right)} \Delta \sigma_{\mathrm{i}}, \quad \Delta \sigma_{\mathrm{i}}=\alpha G b \sqrt{\phi \mathrm{t}}=\alpha G b \sqrt{\Phi}
$$

In the above equation, DBTT is the ductile to brittle transition temperature, $\phi$ is neutron flux, $\Phi$ is fluence $(\phi t), t$ is time of irradiation and T is test temperature. Thus one needs to evaluate the influence of neutron irradiation and test temperature on both the friction and source hardening terms to characterize the change in DBTT. It has been demonstrated from studies on the yield point phenomena, in particular the serrations in dynamic strain aging in various materials including mild steel [8], Amco iron as well as pressure vessel steels $[4,5]$ that the degree of locking of the dislocations by interstitial impurity atoms decreases with exposure to neutron radiation leading to essentially a non-aging steel following exposure to high neutron fluences. This implies that the source hardening decreases following exposure to neutron irradiation [9]. Since friction hardening increases with neutron fluence, these competing effects lead to interesting consequences when examined as a function of the grain size of the material. 


\section{Materials}

\section{Experimental Details}

As described in the introduction, while a number of alloys have been under investigation, we present here experimental work on three different steels and pure iron of varied grain sizes. The chemical compositions of these materials are included in Table 1 and tensile, Charpy and other samples were fabricated from the as-received plates. Different grain sizes were obtained by appropriate thermo-mechanical treatments by the Defense Metallurgical Research Laboratory, India [10] and mainly tensile specimens were machined due to the limitation in the amount of available material.

Table 1. Chemical Compositions of the Steels and Iron

\begin{tabular}{|c|c|c|c|c|c|c|c|c|c|}
\cline { 2 - 10 } \multicolumn{1}{c|}{} & $\mathrm{C}$ & $\mathrm{Mn}$ & $\mathrm{Si}$ & $\mathrm{S}$ & $\mathrm{P}$ & $\mathrm{Cu}$ & $\mathrm{Mo}$ & $\mathrm{Cr}$ & $\mathrm{Ni}$ \\
\hline Armco-Fe & 0.01 & 0.04 & 0.02 & 0.01 & 0.01 & - & - & - & - \\
\hline 1020 & 0.20 & 0.40 & 0.10 & 0.04 & 0.04 & - & - & - & - \\
\hline A516 & 0.20 & 0.98 & 0.02 & 0.02 & 0.02 & 0.24 & 0.03 & 0.20 & 0.16 \\
\hline A588 & 0.20 & 1.20 & 0.31 & 0.04 & 0.04 & 0.22 & 0.05 & - & 0.21 \\
\hline
\end{tabular}

* grain sizes: $50 \mu \mathrm{m}, 110 \mu \mathrm{m}, 190 \mu \mathrm{m}, 300 \mu \mathrm{m}$

\section{Figure 1}

Details of the Materials and Specimen Types

(Radiation Jig \#C : inserted in PULSTAR in 7/92 - imradiated to 7/93)

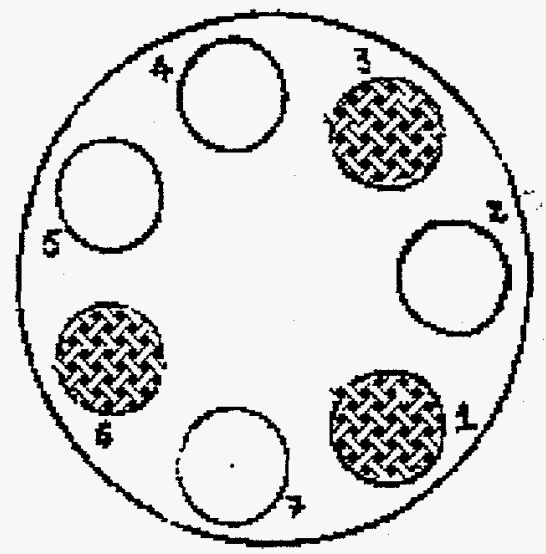

\section{1, 3, 6 : Cadmium Wrapped}

Position Specimen Type: Material (\#)

Position Specimen Type: Material (\#)

C1 C $:$ : A588B (4); Tensile: A588B (8), $\quad$ C4 C $:$ A516/ A36l A354 (2/1/1); Tensile : A36l A516(4) PAS : A588B/ A516/ A36/ A354/ A490/A354/ A490/ (4) PAS : Fe110(1), FIM:

1020 (1) FIM: A516/A354 (1)

$\mathrm{A} 533 \mathrm{~B} / \mathrm{Fe} 50 /(1)$

C2 $C_{V}$ : A588B (4); Tensile : A588B (8), $\quad$ C5 C : A490/ 1020/ Fe50 (1/2/2); Tensile :

A516(6) PAS : A588B/A516/ A36/ A354/ A490/1020/ Fe50/ Fe110 (4)

1020 (1) FIM: A588B/A516/A354 (1) C6 C : Fel10/ Fe300 (2/2); Tensile : Fe50/

C3 CV : A516/1020/Fe50 (1/1/2); Tensile: $1020 / \mathrm{Fe} 190 / \mathrm{Fe} 300(1)$ Dosimeters: Ni, Co

1020/ A36/ A354/ A490/ (1) PAS : A533B/ C7 C : Fe 110/ Fe300 (2/2); Tensile : Fe190/

Fe50/ Fe300 (1)FIM : A533B/Fe50 (1) Fe300/Fe110 (4) Dosimeters : Ni, Co; TC

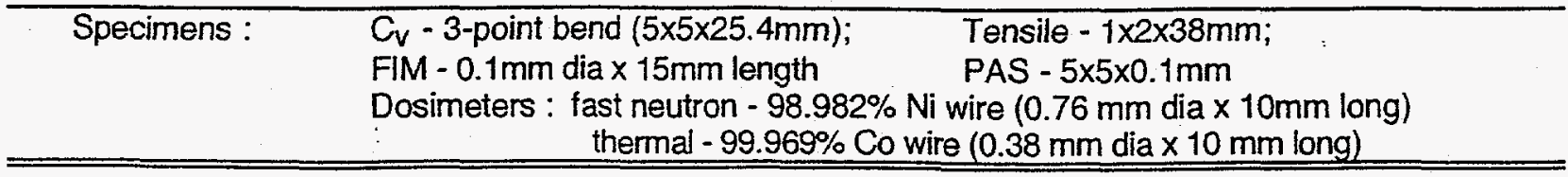


The samples were sealed in evacuated quartz tubes some of which were wrapped with Cd to screen out the low energy neutrons whereas others were exposed to the total neutron spectrum. The prepared specimens were loaded in an aluminum canister as shown in Figure 1 which indicates the matrix of specimens in the capsule $C$. Irradiation of the prepared specimens was performed in the PULSTAR reactor in the Department of Nuclear Engineering at North Carolina State University by loading the aluminum canister adjacent to the core of the reactor. Since inherent structure of the PULSTAR core and reactivity considerations did not permit irradiation in the core, a vertical irradiation tube at core boundary was used as irradiation site. In addition, the vertical position of the jig in the canister was adjusted to the location of the maximum fast $(>1 \mathrm{MeV})$ neutron flux of approximately $1.3 \times 10^{12} \mathrm{n} / \mathrm{cm}^{2}-\mathrm{sec}$ at full power of $1 \mathrm{MW}$. High purity (99.9999\%) $\mathrm{Ni}$ and Co wires were included for evaluating fast $(>0.83 \mathrm{MeV})$ and total $(>0.5 \mathrm{eV})$ flux. These measurements were not made to-date by using the flux monitors in the capsule $C$ but the fast flux has been evaluated from the measurements of the fast flux monitors in capsules $A$ and $B$ which yielded a value of $1.32 \times 10^{12} \mathrm{n} / \mathrm{cm}^{2}$-sec for the fast flux [11] whereas thermal flux is known to be about 12 times the fast flux. Irradiation temperature was the reactor operating temperature, about $323 \mathrm{~K}$ ( 50 $\left.{ }^{\circ} \mathrm{C}\right)$.

The radiation jig $\mathrm{C}$ was left in the reactor for about 11 months and was removed from the reactor in July 1993 with effective full power time of $2.16 \times 10^{6}$ seconds. All the samples along with the aluminum canister became highly radioactive and thus were left in the reactor pool for more than one year for the activity to decay so that the samples can be handled without any remote handling facility. The fast and thermal neutron fluences were estimated to be about $2.8 \times 10^{18} \mathrm{n} / \mathrm{cm}^{2}$ and $3.4 \times 10^{19} / \mathrm{cm}^{2}$ respectively. The tensile tests were performed on a closed loop hydraulic Instron machine at a nominal strain rate of $9.6 \times 10^{-5} \mathrm{sec}^{-1}$ with the load-elongation data collected using a MacIntosh computer.

\section{$\underline{\text { Results and Discussion }}$}

Radiation Hardening (Jigs A \& B)

Tensile data on samples taken from the capsules A \& B with a fast neutron fluence of $\approx 5 \times 10^{17}$ $\mathrm{n} / \mathrm{cm}^{2}$ are summarized in Figure 2 as a bar chart of radiation hardening (increase in the yield stress) which illustrates the relative sensitivity to neutron radiation exposure. A354 and A490 steels exhibited respectively the highest and the least sensitivity while the materials of concern here, namely 1020 and A516 steels were intermediate. These differences are attributed to the chemical composition of the steels, and the microstructure per se is shown to have a nondetectable effect [2]. Because of the availability of a relatively large number of irradiated tensile samples, test temperature dependence of the stress-strain behavior of A516 steel was investigated. Figure 3 depicts the load-elongation curves before and after irradiation which bring out the fact that neutron irradiation suppresses dynamic strain aging leading to relatively smooth stress-strain curves. This implies that the source hardening due to locking of the dislocations by interstitial impurities decreases as reported in a detailed study on silicon-killed mild steel [8]. Since the yield strength increases following radiation exposure, all of this increase arises from the friction hardening due to the radiation enhanced production of obstacles to dislocation motion. Same trends were noted in Armco iron and other steels also.

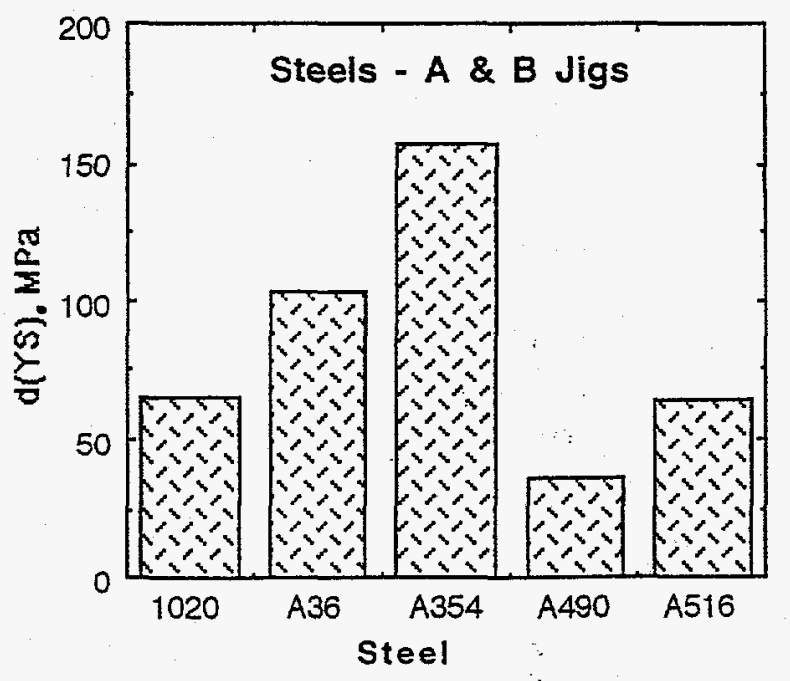

Figure 2

Radiation Hardening of Ferritic Steels 


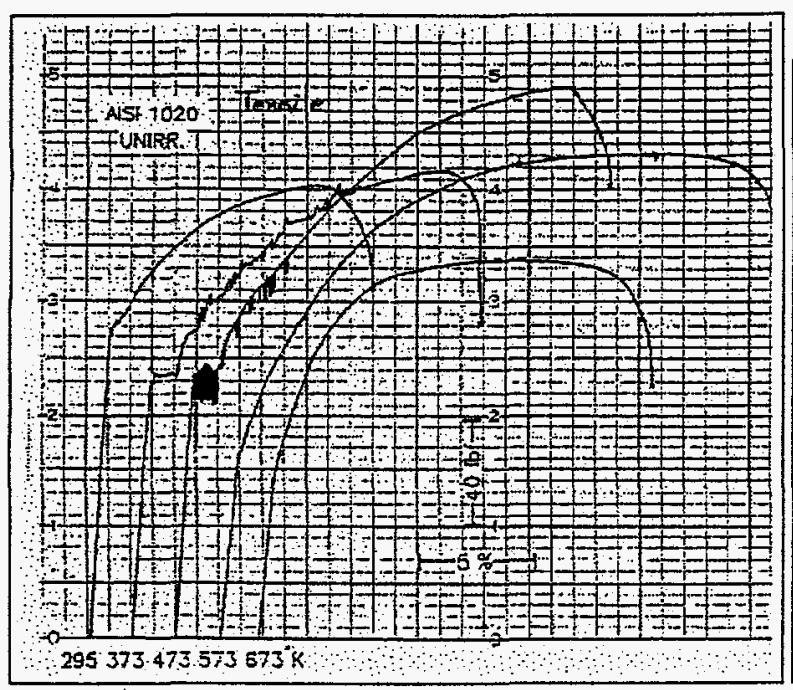

(a)

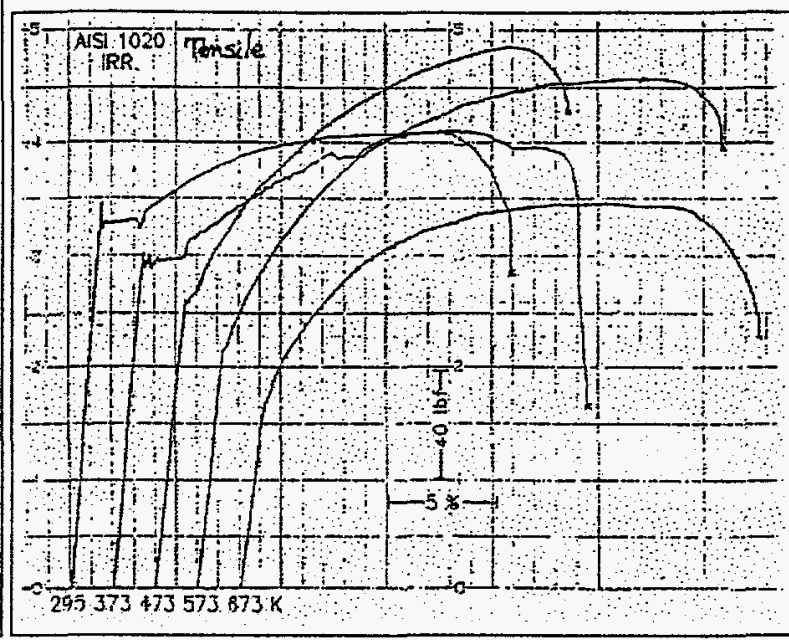

(b)

Load-Elongation Curves for 1020 Steel Before (a) and After (b) Irradiation $\left(5 \times 10^{17} \mathrm{n} / \mathrm{cm}^{2}\right)$

As noted in the introduction, the yield stress is comprised of friction and source hardening components which can be determined by studying the grain-size dependence of the yield stress. Since it is often difficult to obtain materials with different grain sizes particularly for commercial steels, an extrapolation technique [9] is used in deriving these components (Figure 4). Armco iron with different grain sizes helped to check the validity of this extrapolation technique. As shown in Figure 4 the values of the unpinning coefficient $\left(\mathrm{k}_{\mathrm{y}}\right)$ which defines the source hardening derived from these two techniques are essentially the same; this is seen to be valid before and after irradiation. The source hardening term decreased from about 390 to about $300 \mathrm{MPa} \sqrt{\mu \mathrm{m}}$ following radiation exposure to $5 \times 10^{17} \mathrm{n} / \mathrm{cm}^{2}$. Thus the extrapolation technique was used to investigate the effect of test temperature on the friction and source hardening components for Armco-Iron with 50 $\mu \mathrm{m}$ grain size before and after irradiation (Figure 5). In the unirradiated material $\sigma_{\mathrm{i}}$ decreased initially with increase in the test temperature reaching a minimum at maximum serrations in the stress-strain curve. Following radiation exposure, $\sigma_{i}$ increased while at the highest test temperature of $\approx 650 \mathrm{~K}$, annealing of radiation damage is apparent. Correspondingly, the source hardening term exhibited a maximum at the highest degree of locking or serrated yield in the unirradiated material while it decreased following radiation exposure reaching essentially a non-aging condition at temperatures around $500 \mathrm{~K}$.

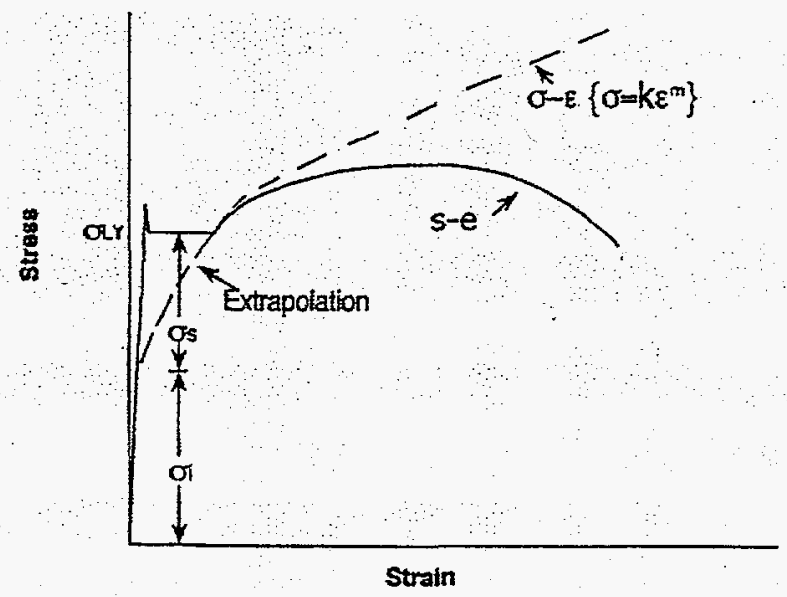

Extrapolation Technique vs
Grain-Size Dependence
\begin{tabular}{ccc}
$k_{y}, M P a \sqrt{\mu m}$ & $(A R M C O-F e)$ \\
Technique & Unirradiated & Iradiated \\
\hline Hall-Petch & 392 & 302 \\
Extrapolation & 389 & 296
\end{tabular}

Figure 4

Evaluation of $\sigma_{\mathrm{i}}$ and $\sigma_{\mathrm{s}}$ using Extrapolation Technique 


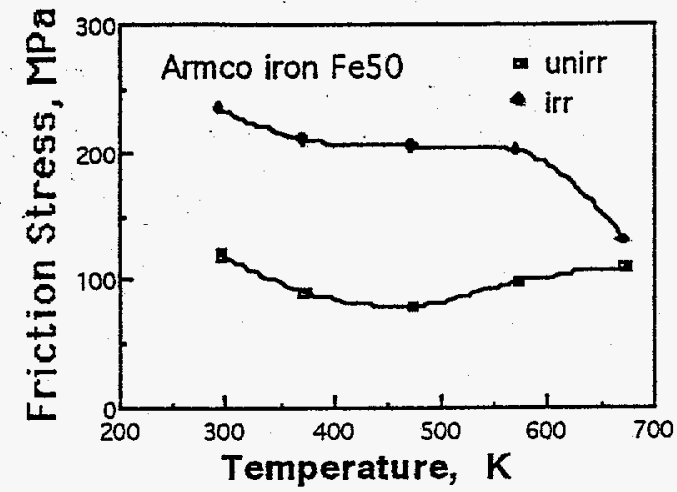

(a)

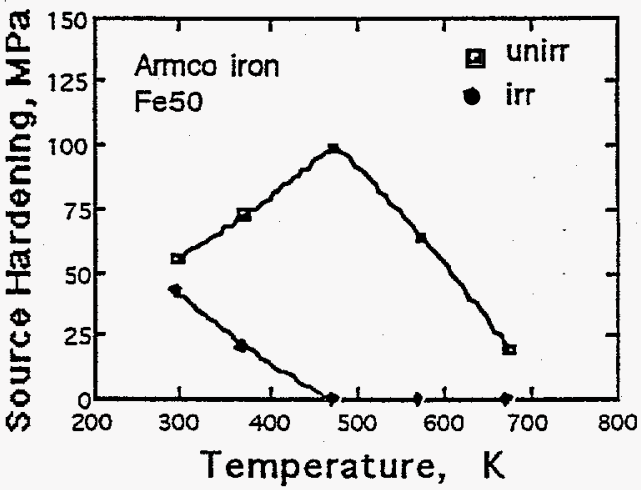

(b)

Effect of neutron irradiation on the temperature variation of friction hardening (a) and source hardening (b) in Armco-Iron

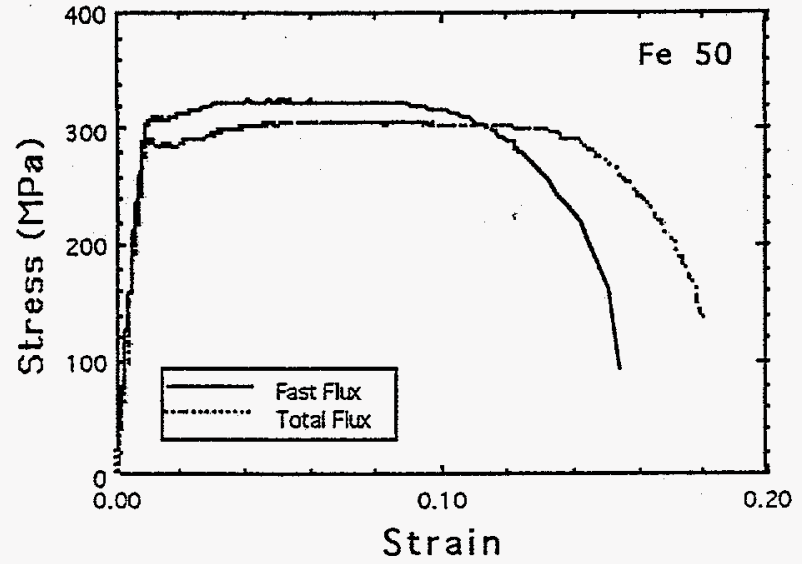

(a) Armco-Fe $(50 \mu \mathrm{m})$

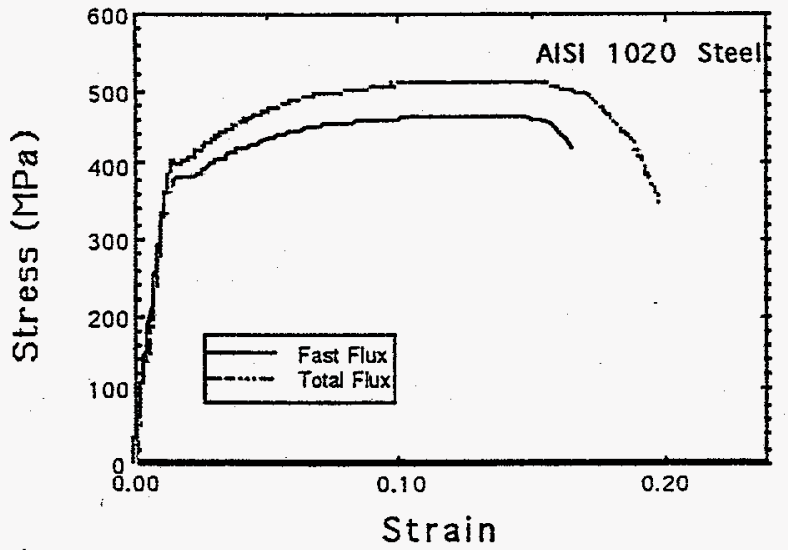

(c) 1020 Steel

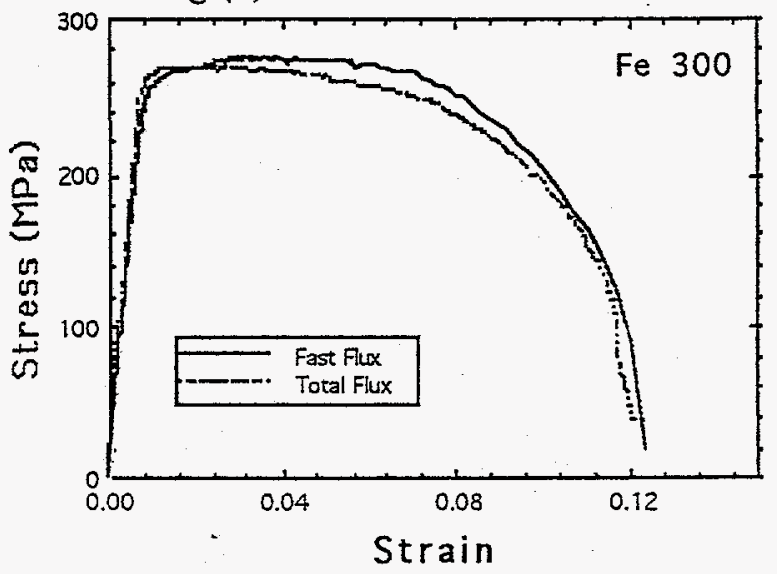

(b) Amco-Fe $(300 \mu \mathrm{m})$

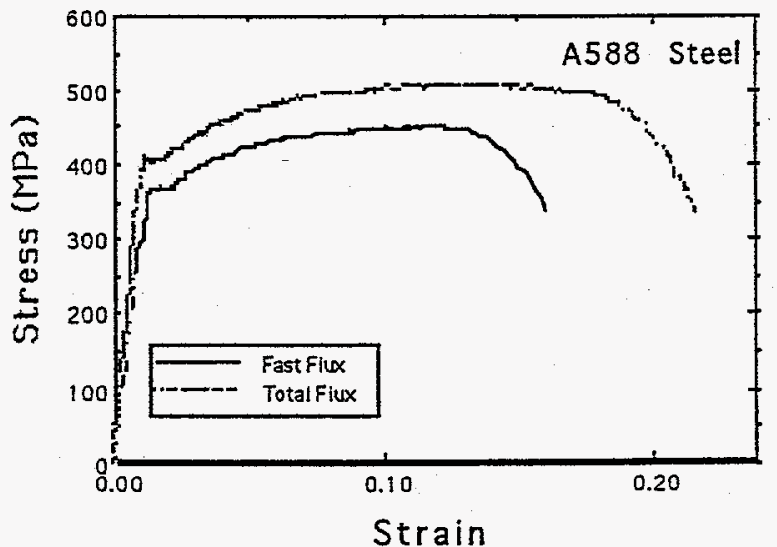

Figure 6

(d) A588 Steel

Effect of Fast (Cd wrapped) and Total Neutron Energy Spectra on Load-Elongation Curves

\section{Effect of Fast versus Total Flux}

Figure 6 compiles room-temperature load-elongation curves for Armco-Iron of small (50 um) and large $(300 \mu \mathrm{m})$ grain sizes and for 1020 and A588 steels obtained on samples taken from the capsule $\mathrm{C}$ with and without cadmium wrapping. Cadmium wrapped materials correspond to fast neutron exposures while without wrapping implies total neutron spectrum which includes fast and thermal. The steel samples reveal that exposures to include low energy $(\leq 0.5 \mathrm{eV})$ neutrons 
resulted in increased strengthening accompanied by increased ductility implying the nonnegligible effect of low energy neutrons on radiation hardening phenomena. Large grained iron samples showed no discernible difference between the fast and total spectra whereas at small grain sizes, reverse was noted with increased hardening and decreased ductility following exposure to only fast neutrons (i.e., cadmium wrapped) compared to the specimens exposed to the neutrons with all energies. At intermediate grain sizes a gradual change is noted while A516 steel exhibited essentially the same effect as 1020 and A588 steels. This is the first time anyone reported this phenomenon of the grain size effect on the fast and total neutron fluences.

Figure 7 is a bar chart depicting the yield strengths of the various steels and Armco iron of different grain sizes following exposure to fast and total neutrons. We note that as grain size decreases from $190 \mu \mathrm{m}$ to $50 \mu \mathrm{m}$, exposure to low energy neutrons along with fast neutrons resulted in lower radiation hardening whereas all three steels showed that the total neutron exposure resulted in increased hardening compared to only fast neutrons.

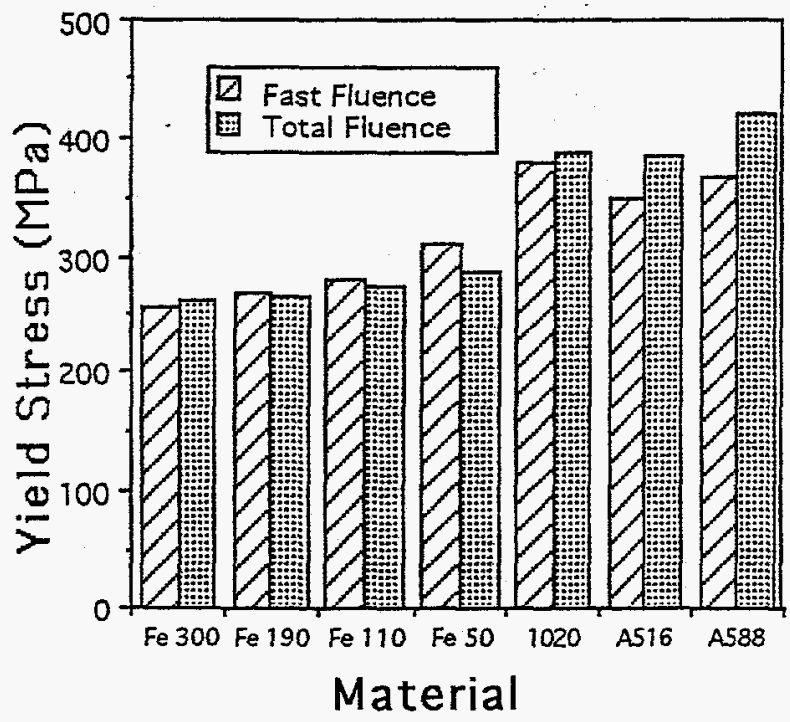

Figure 7

Bar Chart of Yield Stresses for Armco-Iron and Steels Following Fast and Total Neutron Radiation Exposure

We attempt first to explain the grain size effect noted in Armco iron by examining the influence of radiation exposure on the friction and source hardening terms. It is convenient to evaluate these effects by making Hall-Petch plots as in Figure 8 where we plotted the yield stress as a function of $D^{-0.5}$ before irradiation and following radiation exposure to total and fast neutrons. As noted before, we expect the friction hardening to increase and source hardening to decrease due to irradiation which means that the line in Fig. 8 gets displaced to higher values along the $y$-axis (stress) with a decrease in the slope (unpinning constant $\mathrm{k}_{\mathrm{y}}$ and source hardening $\sigma_{s}$ ).

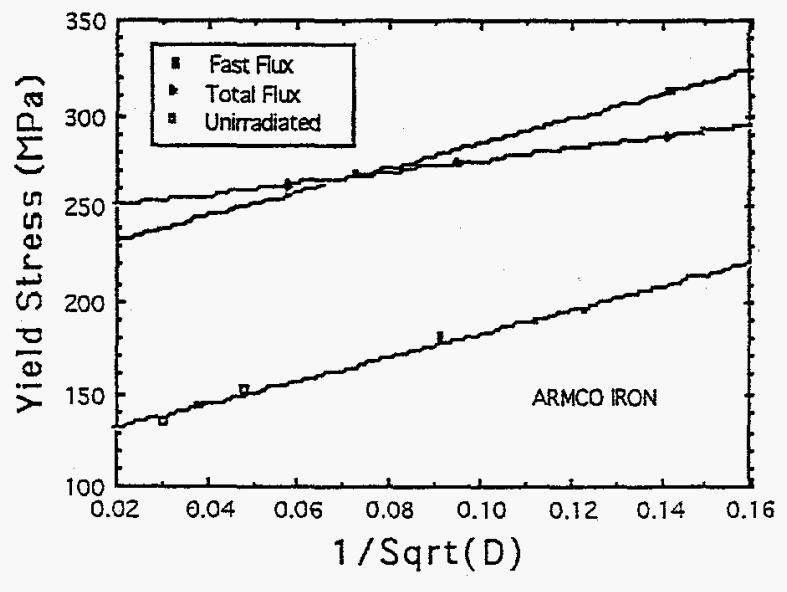

Figure 8

Hall-Petch Plots for Armco-Iron Effects of fast and total neutron fluences are depicted.

Thus following exposure to fast neutrons the slope decreased with extensive hardening. Superimposed effect of low energy neutrons (Cd cut-off of about $0.5 \mathrm{eV}$ ) would be a slight increase in $\sigma_{i}$ which would further increase, albeit by a relatively small amount, the stress or $y$-axis intercept. This is expected to be accompanied by a slight decrease (slightly more than what has been noted following exposure to fast neutrons) in the slope of the Hall-Petch line which implies that the two lines representing the effects of fast and total (fast + low energy) fluences will cross over at a critical grain size below which (means larger values of abscissa) fast neutron fluence would have a slightly larger effect on hardening than exposure to total flux. 
Ferritic steels commonly used in pressure boundary and reactor support applications have very small grain sizes, typically $\leq 50 \mu \mathrm{m}$. But radiation hardening in these materials is opposite to what has been noted in Armco-Fe of small grain sizes. A plausible explanation for this observation lies in the fact that the source hardening and the Petch coefficient $\left(\mathrm{k}_{\mathrm{y}}\right)$ are very small in these steels to start with which is easily noted from the fact that the yield points are not very distinct and also the serration height during dynamic strain aging at appropriate strain-rates and temperatures is relatively small $[5,11]$. This implies that the slope of the Hall-Petch line is very small in the unirradiated condition as depicted in the schematic representation of the grain size effect in these steels (Figure 9); data on grain size effect of these steels are not available to-date.

Once these materials are exposed to fast neutrons, the hardening will all be due primarily to the friction hardening with essentially negligible source hardening thereby resulting in a grain-size independent yield stress (horizontal line in Hall-Petch plot, Fig.9). Exposure to low energy neutrons along with fast neutrons is expected to result in a slight increase in the friction hardening only, thereby resulting in a Hall-Petch line parallel to that noted following exposure to only fast neutrons. Thus exposure to the total neutron energy spectrum in these steels will lead to an additional hardening compared to only fast neutrons irrespective of the grain-size. The partitioning of the yield stress into friction and source hardening terms thus lends explanation and support to the present experimental observations in both Armco-Fe and ferritic steels.

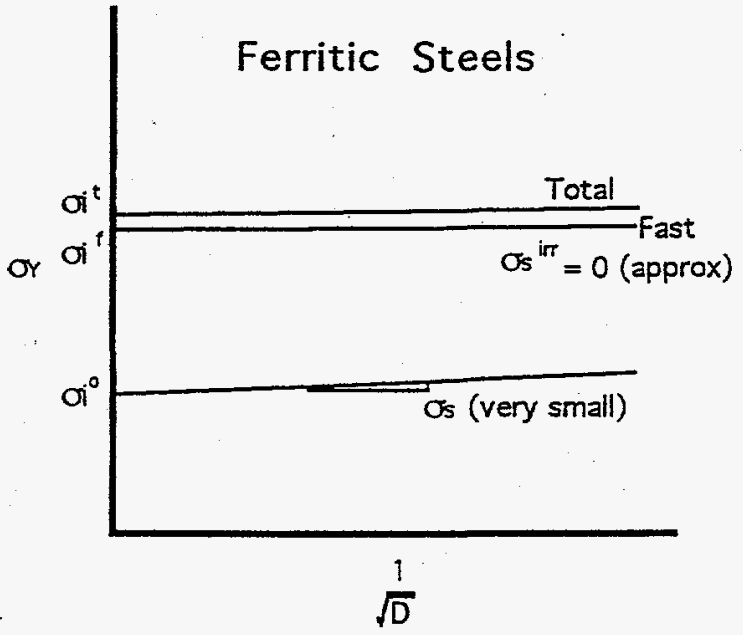

Figure 9

Hall-Petch Plots (Schematic) for Ferritic Steels

- Effects.of fast and total neutron fluences are depicted.

\section{Conclusions}

- Neutron radiation exposure of ferritic steels and Armco iron revealed decreased serrations and yield points due to reduced amounts of interstitial impurities in solution because of their interaction with radiation induced defects.

- Partitioning of the yield stress and quantitative determination of $\sigma_{\mathrm{s}}$ and $\sigma_{\mathrm{i}}$ were possible in Armco iron by studying the effect of grain-size on the yield stress. Thus derived parameters agreed with those evaluated using extrapolation technique lending credibility to the determination of these parameters in steels where grain size effects could not be studied.

- The effect of low ( $\leq 0.5 \mathrm{eV}$ ) energy neutrons on radiation hardening was studied using specimens with and without cadmium wrapping.

- Inclusion of thermal neutrons along with fast does not have the same effect on all grain sizes for Armco iron. For grain sizes below a critical value, exposure to total neutron spectrum resulted in slight reduction of the yield stress when compared to specimens exposed to only fast neutrons. This observation is shown to be consistent with the fact that the source hardening decreases and friction hardening increases with neutron irradiation, along with the observation that low energy neutrons have nonnegligible effect on these parameters. 
- For steels, however, despite their small grain size, low energy neutrons resulted in additional hardening which is explained on the basis that source hardening is very small in these steels before irradiation which decreases to zero following radiation exposure. Thus radiation hardening is entirely due to the friction stress which increases with exposure to fast neutrons. Inclusion of thermal neutrons results in additional, albeit small, increase in friction hardening and thereby the yield stress.

- Further work is warranted to determine the influence of incremental fast and total neutron doses on friction and source hardening terms in pure iron as well as steels.

\section{Acknowledgments}

This work was performed in partial fulfillment of the masters project of Mr. Steve Kass and was supported in part by the Department of Energy - Nuclear Engineering Education Research Grant Program: Nuclear Materials and Fuel Cycle. Acknowledgments are due to Messrs. Ed Preble and Jeff Britt for various discussions and for assistance in the manuscript preparation.

\section{References}

1. G. E. Lucas, G. R. Odette, E. Mader, F. Haggag and R. Nanstad, "Effects of Composition and Temperature on Irradiation Hardening of Pressure Vessel Steels," in Proceedings of the Fifth International Symposium on Environmental Degradation of Materials in Nuclear Power Systems - Water Reactors, American Nuclear Society (1992) pp. 696-703.

2. K. L. Murty, "Interstitial-Impurity Radiation-Defect Interactions in Ferritic Steels," Journal of Metals, October (1985) pp 3439.

3. M. S. Wechsler and K. L. Murty, "Impurity-Defect Interactions and Radiation Hardening and Embrittlement in BCC Metals," Proceedings of Symposium on 'Irradiation-Enhanced Materials Science and Engineering,' Met Trans. 20A (1989) pp. 2637-2649.

4. Youn H. Jung and K. L. Murty, "Effect of Interstitial Impurities on Fracture Characteristics of A533B Class1 Pressure Vessel Steel," in 'Influence of Radiation on Mechanical Properties: 13th International Symposium, 'A ATM STP 956 (1987) pp. 395-407.

5. J. H. Hong and K. L. Murty, "Effect of Dynamic Strain Aging and Neutron Irradiation on Fracture Characteristics of Various Steels and Iron," in Proceedings of ASM Symposium on Microstructure and Mechanical Properties of Aging Materials, Chicago, Oct. 26-29 (1992) pp. 391-397.

6. K. Farrell, S. T. Mahmood, R. E. Stoller and L. K. Mansur, "An Evaluation of Low Temperature Radiation Embrittlement Mechanisms in Ferritic Steels, J. Nucl. Mater. 210 (1994) pp. 268-284.

7. D. R: Olander, Fundamental Aspects of Nuclear Reactor Fuel Elements, Energy Research and Development Administration, Document \#TID-26711-P1 (1976) pp. 418-459.

8. K. L. Murty and E. O. Hall, "Dynamic Strain Aging and Neutron Irradiation in Mild Steel," in 'Irradiation Effects on the Microstructure and Properties of Metals, 'American Society for Testing and Materials STP 611 (1976) pp. 53-71. 
9. K. L. Murty and D. J. Oh, "Friction and Source Hardening in Irradiated Mild Steel," Scripta Met., 17 (1983) pp. 317-320.

10. M. Srinivas, G. Malakondaiah, P. Rama Rao and K. L. Murty, "Fracture Toughness in the Dynamic Strain Aging Regime," Scripta Met. 25 (1991) pp. 2585-2588.

11. J. Hong, R. Zou, J. Britt and K. L. Murty, "Role of Friction and Source Hardening in DSA and Radiation Embrittlement of Ferritic Steels and Iron," Proceedings of SMiRT-12, paper F09/3 (1993). 